\title{
The effects of an insulin-glucose-potassium (IGK) pretreatment on the bupivacaine cardiotoxicity
}

\author{
Jin-Tae Kim ${ }^{1}$, Sol-Mon Yang ${ }^{2}$, and Kook Hyun Lee ${ }^{1}$ \\ Department of Anesthesiology and Pain Medicine, ${ }^{1}$ Seoul National University Hospital, Seoul, ${ }^{2} 17$ th Aeromedical Squadron, \\ Cheongwon-gun, Chungbuk, Korea
}

Background: The purpose of this study is to evaluate the effect of an IGK pretreatment on the cardiotoxicity of bupivacaine.

Methods: Twenty-one anesthetized mongrel dogs were randomly divided into the following three groups: the control group (CG, $n=7$ ), the treatment group (TG, $n=7$ ) and the pretreatment group (PTG, $n=7$ ). For the 30 min of pretreatment period, CG and TG received normal saline, while PTG received an IV bolus of insulin 2 U/kg, followed by an IGK infusion ( $2 \mathrm{U} / \mathrm{kg} / \mathrm{hr}$ of insulin, $0.5-1.5 \mathrm{~g} / \mathrm{kg} / \mathrm{hr}$ of glucose, $1-2 \mathrm{mEq} / \mathrm{kg} / \mathrm{hr}$ of $\mathrm{KCl}$ ). The bupivacaine infusion was started at the rate of $0.5 \mathrm{mg} / \mathrm{kg} / \mathrm{min}$ in all groups after the pretreatment period. CG received normal saline only. In TG, insulin ( $2 \mathrm{U} / \mathrm{kg}$ ) was injected simultaneously with bupivacaine infusion, followed by the IGK infusion as with PTG. The hemodynamic variables and the time duration to reach the mean arterial pressure (MAP) of $60 \mathrm{mmHg}$ were compared.

Results: The bupivacaine infusion decreased the cardiac index, MAP, and heart rate in all three groups. Although insulin concentration was higher in TG than in PTG during bupivacaine infusion, the hemodynamic variables in PTG decreased at the slowest rate. The time taken to reach MAP of $60 \mathrm{mmHg}$ in PTG, TG, and CG was 51.4 $\pm 8.5,36.4 \pm 9.6$, and $27.1 \pm 8.7 \mathrm{~min}$, respectively $(\mathrm{P}<0.05)$.

Conclusions: IGK delays the bupivacaine-induced cardiac depression. However, a pretreatment with IGK is more effective in delaying the bupivacaine-induced hypotension than simultaneous administration, regardless of insulin concentration. (Korean J Anesthesiol 2013; 64: 47-53)

Key Words: Bupivacaine, Cardiotoxicity, Dog, Insulin.

Received: September 13, 2012. Revised: 1st, October 6, 2012; 2nd, October 13, 2012. Accepted: October 15, 2012.

Corresponding author: Kook Hyun Lee, M.D., Ph.D., Department of Anesthesiology and Pain Medicine, Seoul National University Hospital, 28, Yeongeon-dong, Jongno-gu, Seoul 110-744, Korea. Tel: 82-2-2072-2567, Fax: 82-2-747-5639, E-mail: leekh@snu.ac.kr (c) This is an open-access article distributed under the terms of the Creative Commons Attribution Non-Commercial License (http:// creativecommons.org/licenses/by-nc/3.0/), which permits unrestricted non-commercial use, distribution, and reproduction in any medium, provided the original work is properly cited. 


\section{Introduction}

Bupivacaine is an amide-type local anesthetic that is widely used in regional anesthesia and pain management. When bupivacaine is accidentally injected into the blood vessel, serious cardiovascular complications can occur, including cardiac depression, ventricular tachycardia, asystole, and electromechanical dissociation, which are often refractory to conventional treatment [1]. Bupivacaine blocks the $\mathrm{Na}^{+}$ channels during the action potential and also inhibits the transient outward $\mathrm{K}^{+}$current $\left(\mathrm{I}_{\mathrm{to}}\right)$ [2,3]. Bupivacaine interferes with the effective utilization of $\mathrm{Ca}^{2+}$ [4-6]. It also impairs the energy metabolism in a cell [7-9] and causes cardiotoxicity by interfering with the mitochondrial energy transduction $[10,11]$.

Insulin-glucose-potassium (IGK) has been reported to be effective in recovering the cardiac depression induced by a bupivacaine infusion $[12,13]$. Insulin was reported to have a positive inotropic effect in levobupivacaine-induced cardiac depression [14]. The effects of IGK can be explained by an increase in the transient outward $\mathrm{K}^{+}$current $\left(\mathrm{I}_{\mathrm{to}}\right)$ [15] and $\mathrm{Ca}^{2+}$ transport activity of the sarcoplasmic reticulum [16].

The metabolic effects of insulin has been reported to be another mechanism for the effects of IGK on bupivacaineinduced cardiotoxicity [17]. Insulin can increase the cytoplasmic glucose concentration and pyruvate availability to the mitochondria, thereby improving the myocardial energetics and performance [18]. In addition, a pretreatment with IGK has been reported to have a beneficial effect on ischemia by increasing the intracellular glycogen content and decreasing the cardiotoxic plasma free fatty acid $[19,20]$. However, the effects of an IGK pretreatment on the bupivacaine-induced cardiotoxicity have not been studied.

It was hypothesized that IGK administered before the bupivacaine infusion would be more effective in reducing the bupivacaine-induced cardiotoxicity than when administered simultaneously with the bupivacaine, as IGK requires time to take its metabolic effects. The aim of this study was to evaluate the effects of an IGK treatment and IGK pretreatment on bupivacaine-induced cardiotoxicity.

\section{Materials and Methods}

The Animal Care and Use Committee of Seoul National University Hospital approved this study. Twenty-one male mongrel dogs were randomly allocated into three groups: the control group (CG; $23.3 \pm 3.7 \mathrm{~kg}, \mathrm{n}=7$ ), the treatment group (TG; $22.2 \pm 3.8 \mathrm{~kg}, \mathrm{n}=7$ ), and the pretreatment group (PTG; $25.7 \pm 4.3$ $\mathrm{kg}, \mathrm{n}=7$ ).

The dogs were fasted overnight but were given free access to water. Anesthesia was induced with sodium pentobarbital 25 $\mathrm{mg} / \mathrm{kg}$ IV and maintained with a continuous infusion of $5 \mathrm{mg} /$ $\mathrm{kg} / \mathrm{hr}$. After the trachea was intubated with an ID $8.0 \mathrm{~mm}$ cuffed endotracheal tube, the lungs were ventilated with $60 \%$ oxygen in air and adjusted to maintain $\mathrm{PaCO}_{2} 35-45 \mathrm{mmHg}$. Vecuronium $0.2 \mathrm{mg} / \mathrm{kg}$ was then injected followed by $0.02 \mathrm{mg} / \mathrm{kg}$ at 30 min intervals, in order to prevent spontaneous ventilation or movement. A lactated Ringer's solution was infused at a rate of $5 \mathrm{ml} / \mathrm{kg} / \mathrm{hr}$ throughout the experiment. The core temperature was maintained at between $36-38^{\circ} \mathrm{C}$, using a warming blanket and heated fluids.

Both femoral arteries were cannulated with two 20-gauge catheters to continuously monitor the arterial pressure and allow blood sampling. Two intravenous catheters were placed in each antecubital vein for fluid and drug administration (one for phentobarbital and the other for the other drugs except bupivacaine). A fiberoptic pulmonary artery catheter (Opticath ${ }^{\circledR}$, Model P7110-EH, Abbott, Chicago, IL) was inserted through the right external jugular vein to monitor the central venous pressure (CVP) and measure the cardiac index (CI), using the thermodilution method. The systemic vascular resistance index (SVRI) was calculated using a standard formula. The cardiac rhythm and heart rate (HR) were monitored continuously using the standard lead II of the electrocardiogram.

All the dogs had a 30 min of stabilization period before the start of the experiment. For the $30 \mathrm{~min}$ pretreatment period, the dogs in CG and TG received an IV bolus of $1 \mathrm{ml} / \mathrm{kg}$ of normal saline followed by an infusion of $4 \mathrm{ml} / \mathrm{kg} / \mathrm{hr}$. PTG received 2 $\mathrm{U} / \mathrm{kg}$ of regular insulin (Novolin ${ }^{\circledR} \mathrm{R}$, Novo Nordisk, Denmark), followed by an infusion of insulin at a rate of $2 \mathrm{U} / \mathrm{kg} / \mathrm{hr}$. At the same time, $0.5-1.5 \mathrm{~g} / \mathrm{kg} / \mathrm{hr}$ of glucose and $1-2 \mathrm{mmol} / \mathrm{kg} / \mathrm{hr}$ of $\mathrm{KCl}$ were infused to maintain euglycemia and normokalemia, respectively. The rate of the glucose infusion was adjusted to maintain euglycemia $(70-150 \mathrm{mg} / \mathrm{dl})$, according to the blood glucose level (Surestep, Lifescan Inc., USA).

After the pretreatment period, the $0.5 \%$ bupivacaine infusion (Bupivacaine HCL Inj., Myungmun Pharmacy, Korea) was

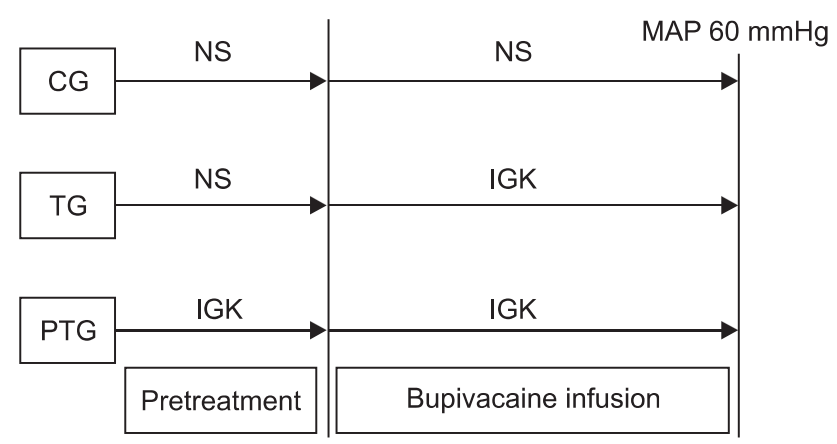

Fig. 1. The experimental design. NS: normal saline, IGK: insulinglucose potassium, CG: control group, TG: treatment group, PTG: pretreatment group, MAP: mean arterial pressure. 
initiated at a rate of $0.5 \mathrm{mg} / \mathrm{kg} / \mathrm{min}$ through a central venous catheter. The infusion of normal saline was continued in CG. In TG, the normal saline infusion was stopped, and insulin $2 \mathrm{U} /$ $\mathrm{kg}$ was injected, followed by an infusion of IGK using the same method as with PTG. In PTG, the IGK was infused continuously throughout the experiment. Sodium bicarbonate was infused at a rate of $2-4 \mathrm{mEq} / \mathrm{kg} / \mathrm{hr}$ through a peripheral venous catheter to maintain an arterial $\mathrm{pH}$ of $7.35-7.45$. Bupivacaine was infused until the mean arterial pressure (MAP) had decreased to $60 \mathrm{mmHg}$ or less for at least 10 consecutive seconds (Fig. 1). All the dogs were sacrificed with $\mathrm{KCl}$ injection after the experiment.

The hemodynamic variables and ECG intervals (PR interval, QRS duration, and QTc interval) were recorded at the baseline, at the start of the bupivacaine infusion, and every 5 min until a MAP of $60 \mathrm{mmHg}$ had been reached. Arterial blood samples were obtained each time to analyze the blood gas, potassium, glucose, epinephrine, norepinephrine, insulin, and bupivacaine concentration. The blood samples for the catecholamine, insulin and bupivacaine concentration were centrifuged at 3,000 rpm for 20 min (Allegra ${ }^{\mathrm{TM}} 6 \mathrm{R}$ centrifuge, Beckman, USA) and stored at $-50^{\circ} \mathrm{C}$ until analyzed. The bupivacaine and catecholamine concentrations were measured by highperformance liquid chromatography. The plasma concentration of insulin was measured by a radioimmunoassay using the porcine insulin antibody.

The data is expressed as the mean \pm standard deviation, and was analyzed using SPSS (SPSS Inc., Chicago, IL). Oneway analysis of the variance and the Tukey test were used to determine the differences between the groups. The comparison between groups was omitted when the number of dogs in any group was less than 5 . The number of dogs remaining in each group with time was compared using a Fisher's exact test. The change over time within each group was evaluated using repeated measures analysis of the variance. The plasma insulin concentration in TG and PTG was compared using a Student's t-test. $P$ value $<0.05$ was considered significant.
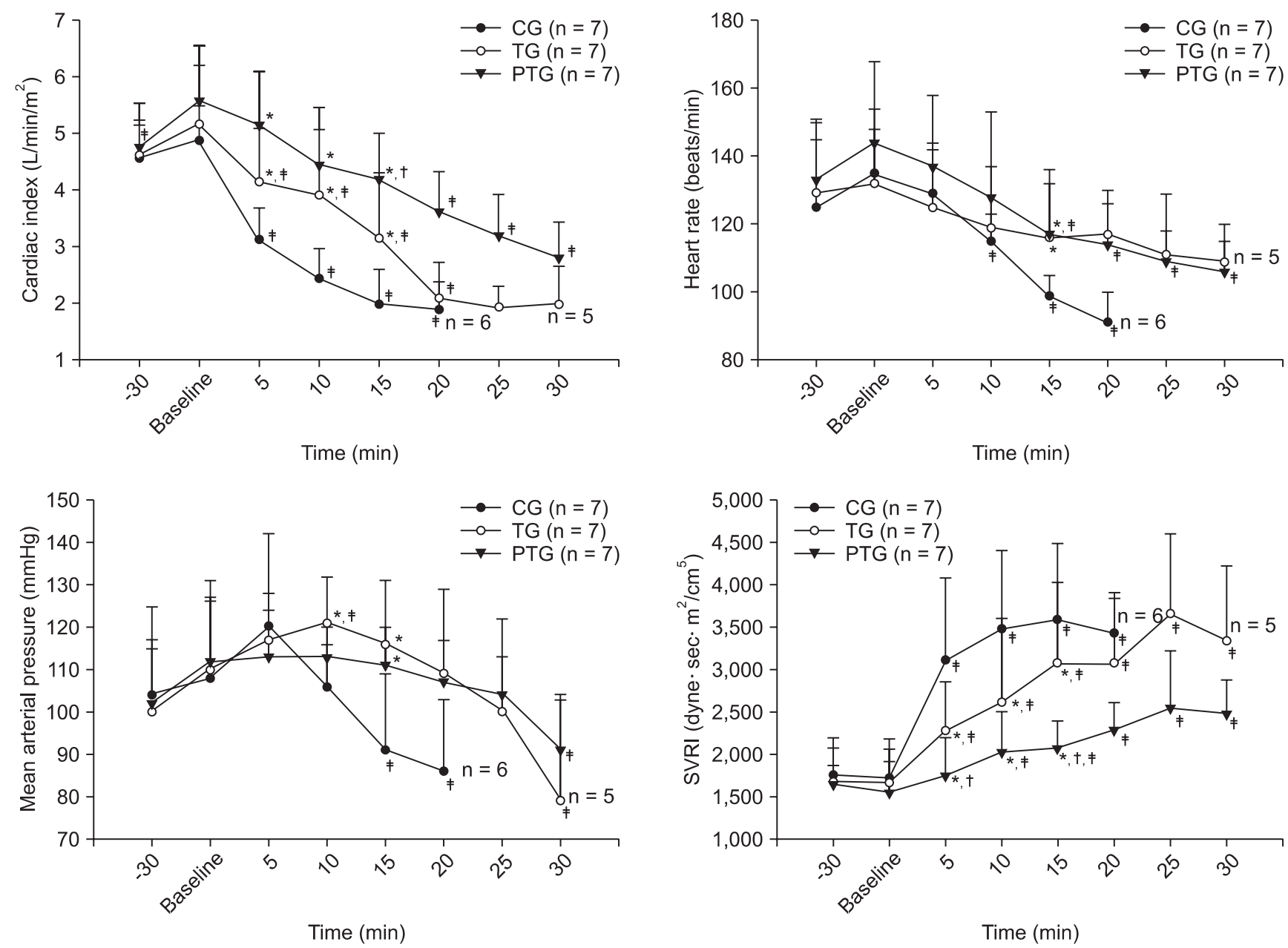

Fig. 2. Sequential change of hemodynamic parameters. CG: control group, TG: treatment group, PTG: pretreatment group, SVRI: systemic vascular resistance index. ${ }^{*} \mathrm{P}<0.05$ vs. $\mathrm{CG},{ }^{\dagger} \mathrm{P}<0.05$ vs. TG, ${ }^{\dagger} \mathrm{P}<0.05$ vs. value at $\mathrm{BI}$. 


\section{Results}

There was no significant difference between the three groups with regard to weight and the hemodynamic variables at the baseline and at the start of bupivacaine infusion. The bupivacaine infusion decreased the CI, HR and MAP in all the dogs. However, the CI in PTG decreased at the slowest rate, compared with CG and TG. The MAP in CG was maintained at the baseline level for $5 \mathrm{~min}$, then decreased abruptly and earlier than the other groups. Compared with CG and TG, the SVRI in PTG increased slowly during the bupivacaine infusion (Fig. 2). Fig. 3 shows the number of dogs remaining in each group.

The data at the end of the experiment (MAP $60 \mathrm{mmHg}$ ) were shown in Table 1. The time for the bupivacaine infusion was

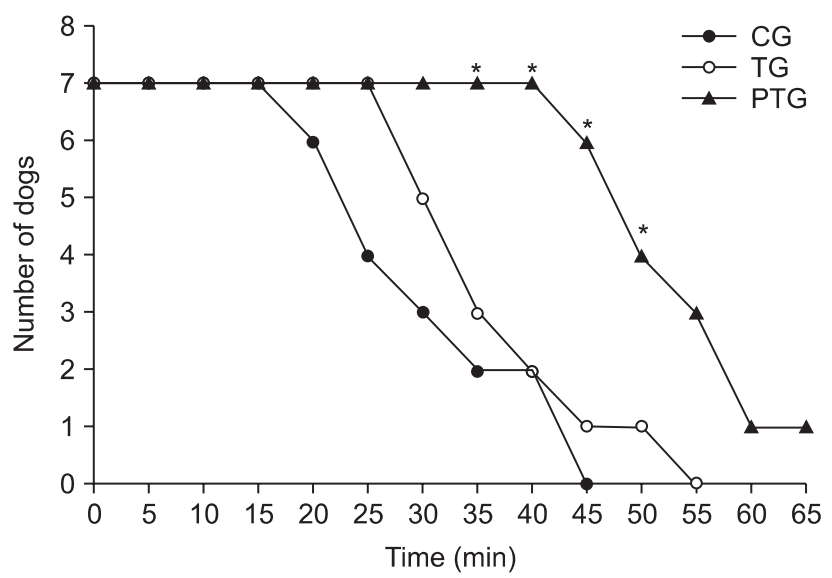

Fig. 3. Number of dogs in the course of the bupivacaine-induced cardiovascular collapse. The dogs were excluded from each group when the mean arterial pressure was decreased by the bupivacaine infusion to $60 \mathrm{mmHg}$. CG: control group, TG: treatment group, PTG: pretreatment group. ${ }^{*} \mathrm{P}<0.05$ survival rate different from $\mathrm{CG}$ or TG. significantly longer in PTG than in TG, and longer in TG than in CG. The bupivacaine concentration in PTG was higher than that in CG. There was no difference in insulin concentration between PTG and TG, at the end of the experiment.

Although the insulin concentration in TG was lower than in PTG at the start of the bupivacaine infusion, the insulin concentration in TG increased and was higher than that of PTG from $5 \mathrm{~min}$ to $20 \mathrm{~min}$ after the bupivacaine infusion $(\mathrm{P}<0.05)$. After $25 \mathrm{~min}$, the insulin concentrations in TG and PTG were similar. The serum potassium, blood glucose, and catecholamine levels were similar in the groups throughout the study (Table 2). The blood gas was maintained at the physiological level without any significant differences between the three groups ( $\mathrm{pH} 7.31-7.49$, $\mathrm{PaO}_{2}$ 298-380 mmHg, $\mathrm{PaCO}_{2} 33-43 \mathrm{mmHg}$ ).

All the dogs had normal sinus rhythm before the bupivacaine infusion. Arrhythmias (A-V block, junctional rhythm, or ventricular ectopy) were detected between $15 \mathrm{~min}$ and $30 \mathrm{~min}$ in 2 dogs in CG and 1 dog in TG. However, arrhythmia appeared 35 min after the bupivacaine infusion in 2 dogs in PTG (Fig. 4). Bupivacaine increased the PR interval, QRS duration, and QTc intervals in all groups. The QRS duration in CG and TG were prolonged after $5 \mathrm{~min}$, whereas it was prolonged after $10 \mathrm{~min}$ in PTG (Table 3).

\section{Discussion}

This study shows that IGK can delay the bupivacaineinduced cardiac depression. Furthermore, the administration of IGK before the bupivacaine infusion is more effective in delaying the bupivacaine-induced cardiotoxicity than the simultaneous administration of bupivacaine with IGK.

IGK could delay the deterioration in the hemodynamics during bupivacaine-induced cardiotoxicity. However, the

Table 1. Mean Values of Parameters at the End of Experiment

\begin{tabular}{|c|c|c|c|}
\hline & CG & TG & PTG \\
\hline Time to MAP $60 \mathrm{mmHg}(\mathrm{min})$ & $27.1 \pm 8.7$ & $36.4 \pm 9.6^{*}$ & $51.4 \pm 8.5^{*, \dagger}$ \\
\hline Bupivacaine $(\mathrm{g} / \mathrm{ml})$ & $16.1 \pm 4.9$ & $17.4 \pm 4.0$ & $19.2 \pm 3.0^{*}$ \\
\hline Dose of bupivacaine (mg/kg) & $13.6 \pm 4.4$ & $18.2 \pm 4.8^{*}$ & $25.7 \pm 4.3^{*}+\dagger$ \\
\hline Insulin (mU/L) & $14 \pm 11$ & $1,896 \pm 712 *$ & $1,862 \pm 715^{*}$ \\
\hline Epinephrine (pg/ml) & $352 \pm 115$ & $381 \pm 193$ & $392 \pm 264$ \\
\hline Norepinephrine (pg/ml) & $787 \pm 442$ & $409 \pm 159$ & $578 \pm 206$ \\
\hline $\mathrm{CI}\left(\mathrm{L} / \mathrm{min} / \mathrm{m}^{2}\right)$ & $1.38 \pm 0.28$ & $1.53 \pm 0.37$ & $1.63 \pm 0.55$ \\
\hline HR (beats/min) & $78 \pm 8$ & $82 \pm 19$ & $79 \pm 11$ \\
\hline SVRI (dyne $\left.\cdot \mathrm{sec} \cdot \mathrm{m}^{2} \cdot \mathrm{cm}^{-5}\right)$ & $2,930 \pm 553$ & $2,672 \pm 506$ & $2,513 \pm 506$ \\
\hline CVP (mmHg) & $7 \pm 3$ & $8 \pm 2$ & $8 \pm 3$ \\
\hline $\mathrm{pH}$ & $7.38 \pm 0.05$ & $7.38 \pm 0.07$ & $7.35 \pm 0.07$ \\
\hline $\mathrm{K}^{+}(\mathrm{mM})$ & $3.8 \pm 0.4$ & $4.1 \pm 0.3$ & $4.3 \pm 0.4$ \\
\hline Glucose (mg/dl) & $95 \pm 9$ & $122 \pm 32$ & $112 \pm 32$ \\
\hline
\end{tabular}

Results are expressed as mean \pm standard deviation. MAP: mean arterial pressure, HR: heart rate, CI: cardiac index, CVP: central venous pressure, SVRI: systemic vascular resistance index, CG: control group, TG: treatment group, $\mathrm{PTG}$ : pretreatment group. ${ }^{*} \mathrm{P}<0.05$ vs. CG, ${ }^{\dagger} \mathrm{P}<0.05$ vs. TG. 


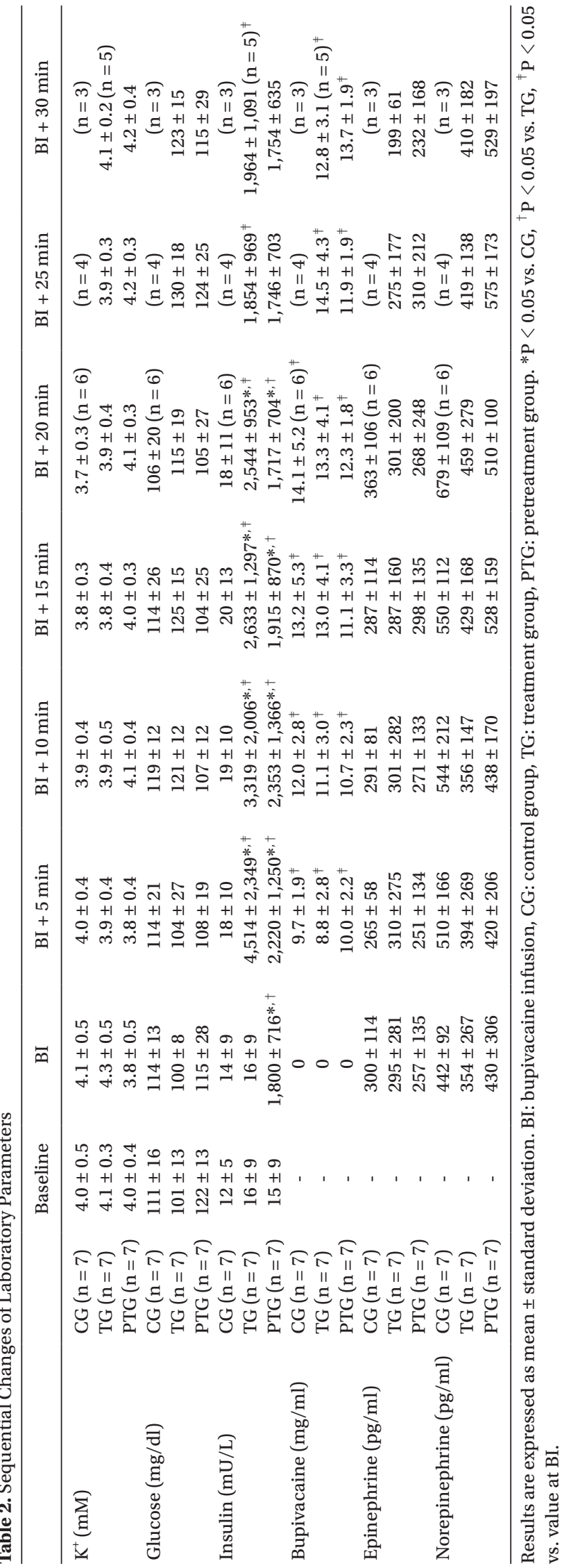

CG

Baseline

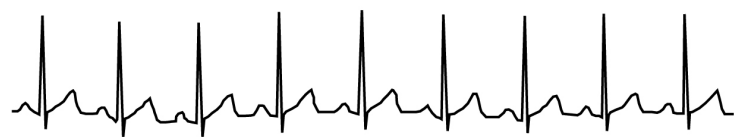

$20 \mathrm{~min}$ after the bupivacaine infusion

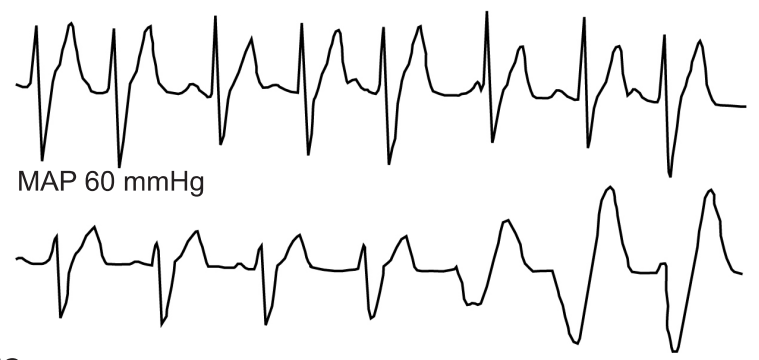

TG

Baseline

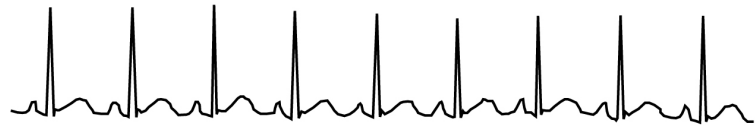

30 min after the bupivacaine infusion
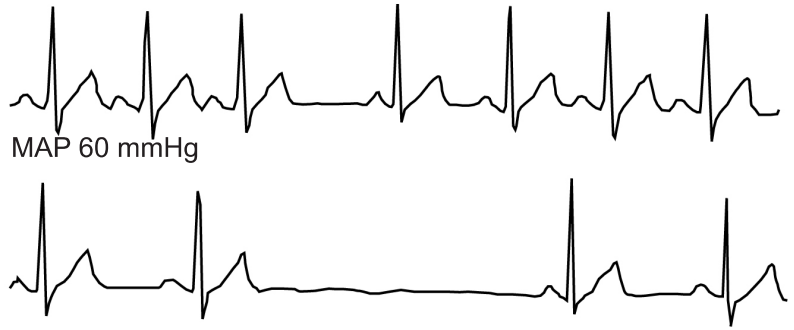

PTG

Baseline

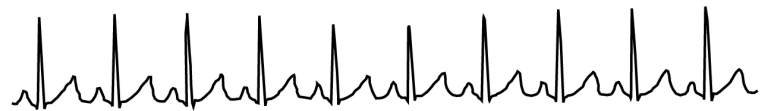

35 min after the bupivacaine infusion
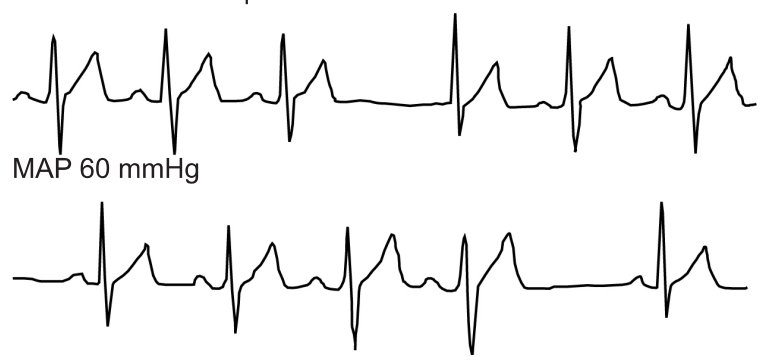

Fig. 4. Electrocardiographic changes occurring during the bupivacaine infusion. A-V block, ventricular ectopy, and large S-wave appeared $20 \mathrm{~min}$ after the bupivacaine infusion in the $\# 5$ dog of CG. Decrease in the MAP to $60 \mathrm{mmHg}$ occurred $25 \mathrm{~min}$ after the bupivacaine infusion. In the \#3 dog of TG, the first arrhythmia appeared $30 \mathrm{~min}$ after the bupivacaine infusion, and the MAP decreased to $60 \mathrm{mmHg}$ 37 min after the bupivacaine infusion. In the \#2 dog of PTG, the first arrhythmia occurred $35 \mathrm{~min}$ after the bupivacaine infusion, and the MAP decreased to $60 \mathrm{mmHg} 50 \mathrm{~min}$ after the bupivacaine infusion. CG: control group, TG: treatment group, PTG: pretreatment group. 
Table 3. Sequential Changes of ECG Parameters

\begin{tabular}{|c|c|c|c|c|c|c|c|c|c|}
\hline & & Baseline & BI & $\mathrm{BI}+5 \mathrm{~min}$ & $\mathrm{BI}+10 \mathrm{~min}$ & $\mathrm{BI}+15 \min$ & $\mathrm{BI}+20 \mathrm{~min}$ & $\mathrm{BI}+25 \mathrm{~min}$ & $\mathrm{BI}+30 \mathrm{~min}$ \\
\hline \multirow[t]{3}{*}{ PRI (msec) } & CG $(\mathrm{n}=7)$ & $100 \pm 16$ & $109 \pm 28$ & $123 \pm 31$ & $133 \pm 17^{*}$ & $134 \pm 16^{*}$ & $134 \pm 10(\mathrm{n}=6)^{*}$ & $(\mathrm{n}=4)$ & $(\mathrm{n}=3)$ \\
\hline & $\mathrm{TG}(\mathrm{n}=7)$ & $100 \pm 12$ & $99 \pm 15$ & $109 \pm 15$ & $125 \pm 23^{*}$ & $129 \pm 12^{*}$ & $135 \pm 23^{*}$ & $142 \pm 30^{*}$ & $155 \pm 29(n=5) *$ \\
\hline & PTG $(n=7)$ & $99 \pm 19$ & $106 \pm 21$ & $125 \pm 24$ & $133 \pm 33^{*}$ & $140 \pm 33^{*}$ & $152 \pm 27^{*}$ & $159 \pm 29 *$ & $153 \pm 20^{*}$ \\
\hline \multirow[t]{3}{*}{ QRS (msec) } & $\mathrm{CG}(\mathrm{n}=7)$ & $55 \pm 8$ & $51 \pm 6$ & $67 \pm 7^{*}$ & $83 \pm 9 *$ & $94 \pm 9 *$ & $95 \pm 9 *$ & $(n=4)$ & $(\mathrm{n}=3)$ \\
\hline & $\mathrm{TG}(\mathrm{n}=7)$ & $51 \pm 10$ & $50 \pm 6$ & $64 \pm 15^{*}$ & $78 \pm 3^{*}$ & $92 \pm 16^{*}$ & $95 \pm 15^{*}$ & $109 \pm 17^{*}$ & $109 \pm 11^{*}$ \\
\hline & PTG $(n=7)$ & $57 \pm 10$ & $60 \pm 15$ & $65 \pm 14$ & $80 \pm 20 *$ & $98 \pm 23 *$ & $102 \pm 26^{*}$ & $109 \pm 23^{*}$ & $111 \pm 25^{*}$ \\
\hline \multirow[t]{3}{*}{ QTc (msec) } & $\mathrm{CG}(\mathrm{n}=7)$ & $333 \pm 51$ & $343 \pm 60$ & $391 \pm 33^{*}$ & $398 \pm 34^{*}$ & $413 \pm 30^{*}$ & $394 \pm 38^{*}$ & $(\mathrm{n}=4)$ & $(\mathrm{n}=3)$ \\
\hline & $\mathrm{TG}(\mathrm{n}=7)$ & $327 \pm 27$ & $345 \pm 29$ & $376 \pm 32$ & $401 \pm 21 *$ & $417 \pm 38 *$ & $403 \pm 30^{*}$ & $444 \pm 59 *$ & $445 \pm 71 *$ \\
\hline & PTG $(\mathrm{n}=7)$ & $330 \pm 31$ & $335 \pm 42$ & $362 \pm 30$ & $392 \pm 43^{*}$ & $414 \pm 54^{*}$ & $416 \pm 47^{*}$ & $453 \pm 70^{*}$ & $461 \pm 53^{*}$ \\
\hline
\end{tabular}

Results are expressed as mean \pm standard deviation. PRI: PR interval, QRS: QRS complex duration, QTc: corrected QT interval, CG: control group, TG: treatment group, PTG: pretreatment group. ${ }^{*} \mathrm{P}<0.05$ vs. value at $\mathrm{BI}$.

effects of the IGK pretreatment cannot be fully explained by these mechanisms. The hemodynamic onset time of insulin is approximately $2-5 \mathrm{~min}$, and the insulin concentration was higher in TG than in PTG for 20 min after the bupivacaine infusion. However, the effect against bupivacaine-induced cardiac toxicity is greater in PTG than in TG. Therefore, it is possible that the additional effect of the IGK pretreatment originated from the $30 \mathrm{~min}$ pretreatment period. In addition to the direct hemodynamic effect, IGK has a beneficial effect on the energy metabolism in the cell influenced by bupivacaine. Insulin can supply the cardiomyocytes with an alternative energy substrate with more efficient utilization of oxygen. It was assumed that the additional IGK effects such as the metabolic effect would require time. There is a delay in the onset of insulin action. It takes approximately $30 \mathrm{~min}$ for insulin to significantly increase the cellular glycogen level and decrease the plasma free fatty acids [21-23]. In fact, the beneficial hemodynamic effect of IGK is reported to be associated with the increase of certain m RNA expression [24].

Under stress conditions, such as drug poisoning induced cardiovascular collapse, the cells are forced to become carbohydrate dependent. Theoretically, there would be increased tolerance to hypoxia if the glycogen content could be increased, and thereby increase the amount of substrate for the anaerobic metabolism. The administration of glucose prior to anoxia has been shown to increase the glycogen concentration and consequently the energy available [25]. The relationship between the beneficial effects of an IGK pretreatment and the glycogen content can be found in patients undergoing mitral valve replacement [26].

During the ischemic condition, high concentrations of plasma-free fatty acids increase the myocardial oxygen requirement, and depress the myocardial performance [27]. Some metabolites of free fatty acids also cause arrhythmia, possibly because they exert some toxicity to the cellular membrane [20]. An infusion of IGK reduces the free fatty acid levels by promoting their esterification into plasma triglycerides [28], which can have a protective effect [29]. Insulin requires time to reduce the free fatty acids.

The acute administration of insulin can stimulate the centrally-mediated sympathetic activity in both animals and humans [30]. However, in this study, the epinephrine and norepinephrine concentrations were similar in the three groups. Therefore, we believe that the positive inotropic effect of insulin is not associated with the release of catecholamine.

There was a difference in the insulin concentration levels of PTG and TG during the first 20 min of bupivacaine infusion. It is due to the pharmacokinetic characteristic of insulin. The bolus injection abruptly increased insulin concentration, and it steadily reached the equilibrium state with continuous insulin infusion. Therefore, insulin concentration in TG was higher than in PTG during bupivacaine infusion, even though the total administered dose was larger in PTG than in TG. The insulin concentration in PTG had already reached the equilibrium during the 30 min of pretreatment period.

There are some limitations in explaining the effects of the IGK pretreatment in this study. First, the intracellular glycogen and plasma-free fatty acid concentrations were not measured. Second, the amount of administered insulin was different between TG and PTG. However, it can be extrapolated that there are some pretreatment effects, because the insulin concentration was higher in TG than in PTG during bupivacaine infusion. Third, in this experiment setting, the dogs were anesthetized and bupivacaine was infused continuously. Therefore, caution needs to be taken when extrapolating this conclusion of the effects of IGK to humans.

In conclusion, although both the prior and simultaneous administration of IGK can delay the bupivacaine-induced cardiac depression, the prior administration of IGK has a superior effect in delaying the bupivacaine-induced cardiac toxicity over the concurrent treatment. This implicates that hyperinsulinemia before bupivacaine administration can mitigate the bupivacaine cardiotoxicity. Further work on the mechanism of insulin pretreatment is needed. 


\section{Acknowledgments}

This study was supported by Seoul National University Hospital 04-2006-0900.

\section{References}

1. Albright GA. Cardiac arrest following regional anesthesia with etidocaine or bupivacaine. Anesthesiology 1979; 51: 285-7.

2. Clarkson CW, Hondeghem LM. Mechanism for bupivacaine depression of cardiac conduction: fast block of sodium channels during the action potential with slow recovery from block during diastole. Anesthesiology 1985; 62: 396-405.

3. Castle NA. Bupivacaine inhibits the transient outward $\mathrm{K}^{+}$current but not the inward rectifier in rat ventricular myocytes. J Parhmacol Exp Ther 1990; 255: 1038-46.

4. Mio Y, Fukuda N, Kusakari Y, Amaki Y, Tanifuji Y, Kurihara S. Comparative effects of bupivacaine and ropivacaine on intracellular calcium transients and tension in ferret ventricular muscle. Anesthesiology 2004; 101: 888-94.

5. Mio Y, Fukuda N, Kusakari Y, Tanifuji Y, Kurihara S. Bupivacaine attenuates contractility by decreasing sensitivity of myofilaments to Ca2+ in rat ventricular muscle. Anesthesiology 2002; 97: 1168-77.

6. Lynch C 3rd. Depression of myocardial contractility in vitro by bupivacaine, etidocaine, and lidocaine. Anesth Analg 1986; 65: 551-9.

7. Terada H, Shima O, Yoshida K, Shinohara Y. Effects of the local anesthetic bupivacaine on oxidative phosphorylation in mitochondria. Change from decoupling to uncoupling by formation of a leakage type ion pathway specific for $\mathrm{H}+$ in cooperation with hydrophobic anions. J Biol Chem 1990; 265: 7837-42.

8. Grouselle M, Tueux O, Dabadie P, Georgescaud D, Mazat JP. Effect of local anaesthetics on mitochondrial membrane potential in living cells. Biochem J 1990; 271: 269-72.

9. Sztark F, Tueux O, Erny P, Dabadie P, Mazat JP. Effects of bupivacaine on cellular oxygen consumption and adenine nucleotide metabolism. Anesth Analg 1994; 78: 335-9.

10. Eledjam JJ, de La Coussaye JE, Brugada J, Bassoul B, Gagnol JP, Fabregat JR, et al. In vitro study on mechanisms of bupivacaineinduced depression of myocardial contractility. Anesth Analg 1989; 69: 732-5.

11. de La Coussaye JE, Bassoul B, Albat B, Peray PA, Gagnol JP, Eledjam JJ, et al. Experimental evidence in favor of role of intracellular actions of bupivacaine in myocardial depression. Anesth Analg 1992; 74: 698-702.

12. Cho HS, Lee JJ, Chung IS, Shin BS, Kim JA, Lee KH. Insulin reverses bupivacaine-induced cardiac depression in dogs. Anesth Analg 2000; 91: 1096-102.

13. Kim JT, Jung CW, Lee KH. The effect of insulin on the resuscitation of bupivacaine-induced severe cardiovascular toxicity in dogs. Anesth Analg 2004; 99: 728-33.

14. Stehr SN, Pexa A, Hannack S, Heintz A, Heller AR, Deussen A, et al. Insulin effects on myocardial function and bioenergetics in L-bupivacaine toxicity in the isolated rat heart. Eur J Anaesthesiol 2007; 24: 340-6.

15. Zierler $\mathrm{K}, \mathrm{Wu} F S$. An early outward transient $\mathrm{K}^{+}$current that depends on a preceding $\mathrm{Na}^{+}$current and is enhanced by insulin. Pflugers Arch 1992; 422: 267-72.

16. Gupta MP, Innes IR, Dhalla NS. Characterization of insulin receptors in cardiac sarcolemmal and sarcoplasmic reticular membranes. J Cardiovasc Pharmacol 1987; 10: 259-67.

17. Weinberg G, VadeBoncouer T. Improved energetics may explain the favorable effect of insulin infusion on bupivacaine cardiotoxicity. Anesth Analg 2001; 92: 1075-6.

18. Tune JD, Mallet RT, Downey HF. Insulin improves cardiac contractile function and oxygen utilization efficiency during moderate ischemia without compromising myocardial energetics. J Mol Cell Cardiol 1998; 30: 2025-35.

19. Devos P, Chiolero R, Van den Berghe G, Preiser JC. Glucose, insulin and myocardial ischaemia. Curr Opin Clin Nutr Metab Care 2006; 9 : 131-9.

20. Doenst T, Bothe W, Beyersdorf F. Therapy with insulin in cardiac surgery: controversies and possible solutions. Ann Thorac Surg 2003; 75: S721-8.

21. Koopmans SJ, Mandarino L, DeFronzo RA. Time course of insulin action on tissue-specific intracellular glucose metabolism in normal rats. Am J Physiol 1998; 274: E642-50.

22. Coon PJ, Rogus EM, Goldberg AP. Time course of plasma free fatty acid concentration in response to insulin: effect of obesity and physical fitness. Metabolism 1992; 41: 711-6.

23. Rogers WJ, Russell RO Jr, McDaniel HG, Rackley CE. Acute effects of glucose-insulin-potassium infusion on myocardial substrates, coronary blood flow and oxygen consumption in man. Am J Cardiol 1977; 40: 421-8.

24. Ranasinghe AM, McCabe CJ, Quinn DW, James SR, Pagano D, Franklyn JA, et al. How does glucose insulin potassium improve hemodynamic performance? Evidence for altered expression of beta-adrenoreceptor and calcium handling genes. Circulation 2006; 114(1 Suppl): 1239-44.

25. Scheuer J, Stezoski SW. Protective role of increased myocardial glycogen stores in cardiac anoxia in the rat. Circ Res 1970; 27: 83549.

26. Besogul Y, Tunerir B, Aslan R, Isiksoy S, Colak O, Kural T. Clinical, biochemical and histochemical assessment of pretreatment with glucose-insulin-potassium for patients undergoing mitral valve replacement in the third and fourth functional groups of the New York Heart Association. Cardiovasc Surg 1999; 7: 645-50.

27. Fath-Ordoubadi F, Beatt KJ. Glucose-insulin-potassium therapy for treatment of acute myocardial infarction: an overview of randomized placebo-controlled trials. Circulation 1997; 96: 1152-6.

28. Opie LH, Owen P. Effect of glucose-insulin-potassium infusions on arteriovenous differences of glucose of free fatty acids and on tissue metabolic changes in dogs with developing myocardial infarction. Am J Cardiol 1976; 38: 310-21.

29. Rogers WJ, Segall PH, McDaniel HG, Mantle JA, Russell RO Jr, Rackley CE. Prospective randomized trial of glucose-insulinpotassium in acute myocardial infarction. Effects on myocardial hemodynamics, substrates and rhythm. Am J Cardiol 1979; 43: 801-9.

30. Scherrer U, Sartori C. Insulin as a vascular and sympathoexcitatory hormone: implications for blood pressure regulation, insulin sensitivity, and cardiovascular morbidity. Circulation 1997; 96: 4104-13. 